\title{
Cathodic Reduction of Caffeine: Synthesis of an Amino-Function- alized Imidazole from a Biobased Reagent
}

\author{
Fabiana Pandolfi \\ Isabella Chiarotto \\ Leonardo Mattiello \\ Daniele Rocco \\ Feroci Marta* (1) \\ Dept. Scienze di Base e Applicate per l'Ingegneria, Sapienza \\ University, Via del Castro Laurenziano, 7, 00161, Rome, Italy \\ marta.feroci@uniroma1.it
}

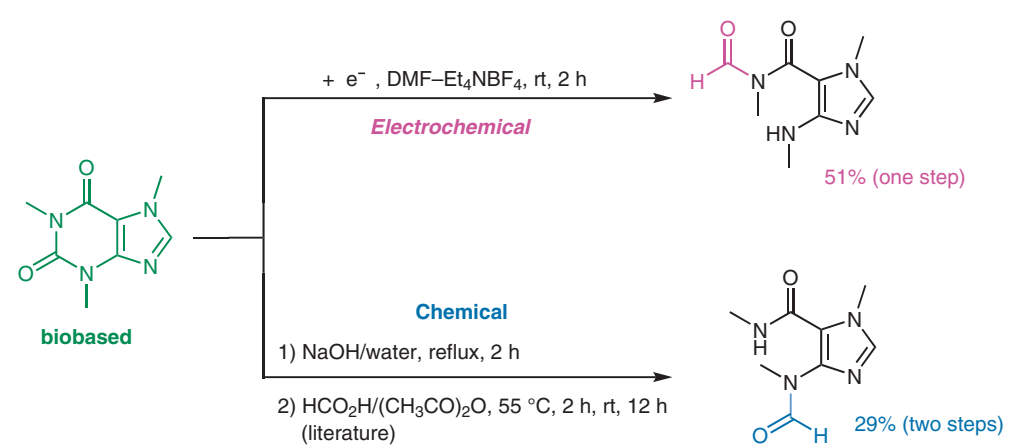

Received: 09.02.2019

Accepted after revision: 24.03.2019

Published online: 10.04 .2019

DOI: 10.1055/s-0037-1611483; Art ID: st-2019-b0076-c

Abstract The electrochemical reduction of caffeine, never carried out previously, yielded in DMF- $\mathrm{Et}_{4} \mathrm{NBF}_{4} \mathrm{~N}$-formyl- $\mathrm{N}$,1-dimethyl-4-(methylamino)- $1 \mathrm{H}$-imidazole-5-carboxamide, a highly functionalized imidazole product derived from the opening of the uracil ring. This reactivity is different from that of the methylated salt of caffeine, the cathodic reduction of which leads to the opening of the imidazole ring. Moreover, the product obtained by cathodic reduction, formylated at the exocyclic amide nitrogen, is different from that formed by treatment in an aqueous solution of sodium hydroxide followed by formylation. The latter is formylated at the exocyclic amine nitrogen.

Key words cathodic reduction, caffeine, ring opening, electrolysis, cyclic voltammetry

Caffeine is a well known, natural, and widespread product, found in various parts of plants from South America and East Asia (the most famous are tea, cocoa, and coffee plants). ${ }^{1}$ It is a xanthine (1,3,7-trimethyl-3,7-dihydro- $1 H$ purine-2,6-dione) and thus its structure can be seen as the fusion of an uracil ring with an imidazole one; it is a biobased and renewable reagent, quite cheap, and convenient as a starting material in organic synthesis.

The majority of literature papers reports the use of caffeine as a starting material for the synthesis of the corresponding NHC ( $N$-heterocyclic carbene) metal complexes, after its transformation into the corresponding caffeinium salt and deprotonation at the C2 atom of the imidazolium ring. ${ }^{2}$ Nonetheless, a few papers report the use of caffeine as a starting material in organic synthesis. ${ }^{3}$ The very small number of papers reporting the use of this xanthine as a starting material resides probably in the very high chemical stability of this molecule. In fact, quite drastic conditions are needed to make caffeine react (ozone, ${ }^{4}$ very basic solutions, ${ }^{5}$ etc).
On the other hand, electrochemical oxidation of caffeine is quite easy [its oxidation peak potential in cyclic voltammetry (CV) is around $+1.4 \mathrm{~V}$ (vs SCE), depending on the electrochemical system used], so that very often the caffeine presence is evidenced by electrochemical methods. ${ }^{6}$ Despite the large number of papers present in the literature on the electrochemical oxidation of caffeine, its electrochemical reduction has never been reported (to the best of our knowledge). In order to fill this lack of information and to explore the possibility to use caffeine as a biobased starting material for a cathodic electrosynthesis, we decided to study the electrochemical reduction of caffeine.

Recently, we reported the cathodic behavior of methylcaffeinium iodide in DMF solution, carrying out cyclic voltammetries (and DPVs) and preparative electrolyses. ${ }^{7}$ The product of the electrochemical reduction was a substituted uracil (hymeniacidin) derived from the hydrolysis of the corresponding electrogenerated $\mathrm{N}$-heterocyclic carbene (Scheme 1).

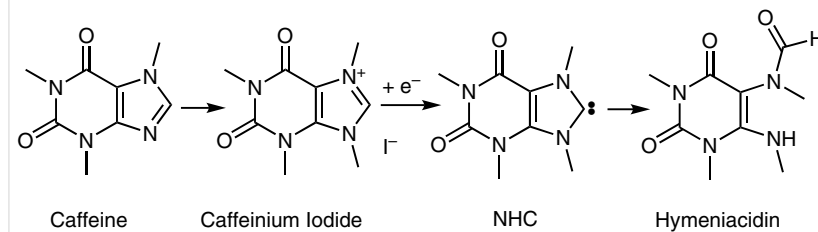

Scheme 1 Electrochemical reduction of caffeinium iodide to hymenia$\operatorname{cidin}^{7}$

Hymeniacidin (a natural product) derives from the imidazole ring opening; in fact, the electrochemical reduction of the caffeinium cation involves the scission of the $\mathrm{C} 2-\mathrm{H}$ bond of the imidazolium moiety, which bears a smaller negative charge. On the other hand, in the case of caffeine 
(which is not charged) the reduction site should be on the uracil ring, most probably at the urea carbonyl group, leading to a completely different product in case of ring opening.

With this in mind, we carried out the cathodic reduction of caffeine in DMF, after a careful analysis by cyclic voltammetry, in order to choose the best experimental conditions for this electrochemical reduction.

Cyclic voltammetric curves of caffeine (reported in the Supporting Information) reveal that it is not possible to selectively reduce caffeine in the solvent-supporting electrolyte systems taken into consideration by us. In particular, we used MeCN, DMF, and the ionic liquid BMIM-BF 4 (1-butyl-3-methylimidazolium tetrafluoroborate) as the solvent, with $\mathrm{Et}_{4} \mathrm{NBF}_{4}, \mathrm{Bu}_{4} \mathrm{NBF}_{4}$, and $\mathrm{NaClO}_{4}$ as supporting electrolyte. Except for the CVs in $\mathrm{DMF}-\mathrm{NaClO}_{4}$ at a GC cathode, all the other CVs show that the reduction of both caffeine and the solvent-supporting electrolyte occurs at about the same

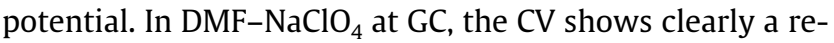
duction peak for caffeine at $-2.53 \mathrm{~V}$ vs SCE (see Figure S2 of the Supporting Information). At this potential, the reduction of the solvent-supporting electrolyte just begins (onset potential). We thus started the study of the cathodic reduction of caffeine using DMF- $\mathrm{NaClO}_{4}$ as the solvent-supporting electrolyte. The results of these electrolyses are reported in Table 1, entries 1-5.

Table 1 Electrochemical Reduction of Caffeine. Effect of Various Parameters on the Product Yield ${ }^{\mathrm{a}}$

\begin{tabular}{cllccc}
\hline Entry & Electrolyte & $\mathrm{E} / \mathrm{l}^{\mathrm{b}}$ & $\mathrm{F}^{\mathrm{c}}$ & $\begin{array}{l}\text { Product, } \\
\%^{\mathrm{d}}(\mathrm{CE}, \%)^{\mathrm{e}}\end{array}$ & $\begin{array}{l}\text { Caffeine } \\
(\%)^{f}\end{array}$ \\
\hline $1^{\mathrm{g}}$ & $\mathrm{NaClO}_{4}$ & $-2.55 \mathrm{~V}$ & 2 & $12(12)$ & 83 \\
2 & $\mathrm{NaClO}_{4}$ & $-2.55 \mathrm{~V}$ & 2 & $21(21)$ & 74 \\
3 & $\mathrm{NaClO}_{4}$ & $-2.55 \mathrm{~V}$ & 3 & $41(27)$ & 43 \\
$4^{\mathrm{h}}$ & $\mathrm{NaClO}_{4}+\mathrm{H}_{2} \mathrm{O}$ & $-2.55 \mathrm{~V}$ & 3 & $44(29)$ & 39 \\
5 & $\mathrm{NaClO}_{4}$ & $10 \mathrm{~mA} \mathrm{~cm}{ }^{-2}$ & 3 & $42(28)$ & 47 \\
6 & $\mathrm{Et}_{4} \mathrm{NBF}_{4}$ & $15 \mathrm{~mA} \mathrm{~cm}^{-2}$ & 1 & $28(56)$ & 71 \\
7 & $\mathrm{Et}_{4} \mathrm{NBF}_{4}$ & $15 \mathrm{~mA} \mathrm{~cm}^{-2}$ & 2 & $40(40)$ & 46 \\
8 & $\mathrm{Et}_{4} \mathrm{NBF}_{4}$ & $15 \mathrm{~mA} \mathrm{~cm}^{-2}$ & 3 & $47(31)$ & 32 \\
9 & $\mathrm{Et}_{4} \mathrm{NBF}_{4}$ & $15 \mathrm{~mA} \mathrm{~cm}^{-2}$ & 4 & $38(19)$ & 28 \\
$10^{\mathrm{h}}$ & $\mathrm{Et}_{4} \mathrm{NBF}_{4}+\mathrm{H}_{2} \mathrm{O}$ & $15 \mathrm{~mA} \mathrm{~cm}^{-2}$ & 3 & $51(34)$ & 35 \\
$11^{\mathrm{h}}$ & $\mathrm{Bu}_{4} \mathrm{NBF}_{4}+\mathrm{H}_{2} \mathrm{O}$ & $15 \mathrm{~mA} \mathrm{~cm}^{-2}$ & 3 & $49(33)$ & 38 \\
\hline
\end{tabular}

${ }^{a}$ All the electrolyses were carried out in a two-compartment cell, by using $\mathrm{Pt}$ electrodes, at rt, under an inert atmosphere. SCE reference electrode was used when necessary. Caffeine $(0.5 \mathrm{mmol})$ in DMF $(5.0 \mathrm{~mL}, 0.1 \mathrm{M}$ electrolyte) was the catholyte; DMF ( $2.0 \mathrm{~mL}, 0.1 \mathrm{M}$ electrolyte) was the anolyte.

${ }^{b}$ Potentiostatic (E) or galvanostatic (I) conditions.

c Number of Faradays per mole of caffeine passed through the cell.

${ }^{d}$ Product as described later in the paper. The yield was calculated from the NMR spectrum of the crude reaction, see later in the paper.

e Current efficiency, considering a two-electron process.

${ }^{f}$ Recovered caffeine.

${ }^{9}$ Glassy carbon (GC) was used as the cathode, instead of platinum.

${ }^{\mathrm{h}}\left[\mathrm{H}_{2} \mathrm{O}\right]=0.2 \mathrm{M}$.
The first experiment was carried out at a constant potential of $-2.55 \mathrm{~V}$ vs SCE (caffeine peak potential in cyclic voltammetry), on a glassy carbon (entry 1) cathode. The current flow was stopped after $2 \mathrm{~F}$ (the electrolysis was quite slow and the current after $2 \mathrm{~F}$ was almost the same as that of the beginning of the electrolysis). After evaporation of the catholyte solvent, the crude reaction product was analyzed by ${ }^{1} \mathrm{H}$ NMR spectroscopy. The ${ }^{1} \mathrm{H}$ NMR spectrum in $\mathrm{CD}_{3} \mathrm{OD}$ showed, along with the NMR signals relative to caffeine, a series of singlets, relative to the methyl groups of a different product. Because of the very low yield of the product (12\%, see later) and the long duration of electrolysis (which is probably due to molecule adsorption on the surface of glassy carbon cathode), we decided to use platinum as the cathode material, despite the CV shows the co-reduction of reagent and supporting electrolyte (Figure S3). We chose the same potential as that of entry 1 . The current flow was stopped after $2 \mathrm{~F}$ (entry 2) and after $3 \mathrm{~F}$ (entries 3 and 4 ). The current after $3 \mathrm{~F}$ was still high, which suggests that the co-reduction of the supporting electrolyte was occurring. The low current efficiencies confirm that this was the case. The galvanostatic electrolysis gave a similar yield of product (entry 5) as the potentiostatic electrolyses (entries 3 and 4). Workup of the catholyte showed the presence of the same product as that obtained in entry 1.

The possibility of forming a product deriving from the opening of the imidazole ring (analogue of hymeniacidin) was excluded, because of the presence of a methyl signal at $3.90 \mathrm{ppm}$ (see Supporting Information), very similar to the that of $\mathrm{N}-\mathrm{CH}_{3}$ of the imidazole ring of caffeine (the hymeniacidin lowest field methyl signal is at $3.37 \mathrm{ppm}$ ). Moreover, a signal at $8.52 \mathrm{ppm}$ led us think of a formamide moiety. Unexpectedly, the integral of this signal diminished with time, rendering us uncertain about the real presence of a formyl group. Furthermore, the MS spectra (ESI and EI) show an $\mathrm{m} / \mathrm{z}$ value of 168 , corresponding to the relative mass of caffeine with a loss of 26 (possibly $-\mathrm{CO}+2 \mathrm{H}$, thus a ring opening). Keeping these considerations in mind, we identified three possible structures for this product (Scheme 2), deriving from the uracil ring opening. Amine A (caffeidine) ${ }^{8}$ was considered in view of the mass spectra (relative molecular mass 168). This amine is the product obtained by strongly basic hydrolysis of caffeine. Products $\mathbf{B}$ and $\mathbf{C}$ could derive from the reduction of the urea carbonyl group of caffeine, yielding the corresponding alcohol (similar to a hemiaminal) and subsequent ring opening (see later). Products $\mathbf{A}$ and $\mathbf{B}$ were previously reported in the literature by Keyzers and coworkers. ${ }^{5}$

In particular, amine A was obtained in 56\% yield from caffeine by treatment with $\mathrm{NaOH} 2 \mathrm{M}$ for two hours at reflux, while formamide $\mathbf{B}$ was obtained from $\mathbf{A}$, in $51 \%$ yield, after treatment with formic acid and acetic anhydride at $55{ }^{\circ} \mathrm{C}$ for two hours and at rt for 12 hours. 


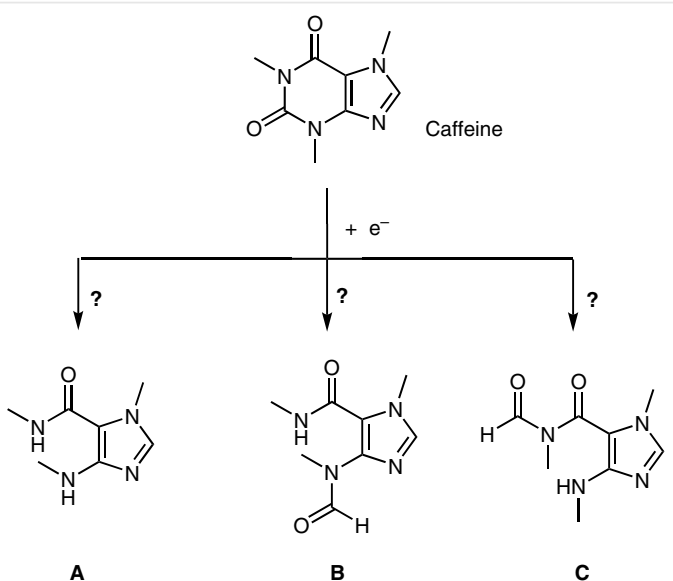

Scheme 2 Possible products from the cathodic reduction of caffeine

We thus synthesized $\mathbf{A}$ and $\mathbf{B}$ following the literature methods in order to compare their NMR spectra and TLC behavior with those of the electrolysis product. Product $\mathbf{A}$ was immediately excluded, as its NMR spectra were very different from those of the electrolysis product (both in field and multiplicity of signals, see Supporting Information); interestingly, Keyzers and co-workers ${ }^{5}$ reported an $\mathrm{H} / \mathrm{D}$ exchange in $\mathrm{CD}_{3} \mathrm{OD}$ for the formyl hydrogen atom of product $\mathbf{B}$, yielding a decrease of the integral of this signal during time (the same phenomenon observed by us).

Nonetheless, the NMR signals (both ${ }^{1} \mathrm{H}$ and ${ }^{13} \mathrm{C}$ ) were slightly different, although similar. Moreover, Keyzers and co-workers ${ }^{5}$ isolated $\mathbf{B}$ as a mixture of rotamers (due to the partial double bond character of $\mathrm{N}-\mathrm{CHO}$ bond, leading to two possible rotamers), whereas we had only one set of signals. Furthermore, the mass spectrum of $\mathbf{B}$ gave the $m / z$ value of its molecular weight, whereas the mass spectrum of our product gave a fragment corresponding to a decarbonylation, both in the EI and ESI mode, the latter evidencing an instability of our product under mass spectrum recording conditions.

These results led us to propose structure $\mathbf{C}$ for the electrolysis product, for which both easy decarbonylation reaction and the absence of rotamers are predictable.

$\mathrm{N}$-Formylimides (such as product C) are important starting materials for the synthesis of enamides, ${ }^{9} \beta$-amidoacrylates, ${ }^{10} \beta$-amidoacrylonitriles, ${ }^{11}$ etc.

Because of the low yield in this new product (21\%, Table 1 , entry 2), it was quite difficult to obtain it in pure form. Hence, we decided to change various parameters in order to try to enhance the yield. Given the closeness of the onset reduction potential of the solvent-electrolyte and the highly negative reduction potential of caffeine, the selectivity (41-42\% yield of C, Table 1, entries 3 and 5 ) after about $50 \%$ conversion is relatively good. In DMF- $\mathrm{NaClO}_{4}$, we cannot exclude the reduction of sodium cations at the electrode and the following reduction of caffeine by reduced sodium (indirect reduction). Water is much easier to reduce than sodium cations. Furthermore, an irreversible ring opening (Scheme 3 ) requires the presence of protons and water is a good proton donor. Thus, we added water $(0.2 \mathrm{M}$ concentration) to the catholyte. This resulted in a small increase in yield (Table 1 , entry 4 ).

A change of supporting electrolyte to the common $\mathrm{Et}_{4} \mathrm{NBF}_{4}$ seemed to increase the electrochemical performances, with a yield in $\mathbf{C}$ which varied with the number of Faradays (entries 6-9) and reached 47 and $51 \%$ after $3 \mathrm{~F}$ in the absence and in the presence of water, respectively (entries 8 and 10). ${ }^{12}$

The use of $\mathrm{Et}_{4} \mathrm{NBF}_{4}$ should avoid the possible indirect reduction of caffeine, as the cathodic reduction of tetraethylammonium cations leads to the formation of $\mathrm{Et}_{3} \mathrm{~N}^{13} \mathrm{~A}$ mechanism for this two-electron cathodic reduction is proposed in Scheme 3.

The ring opening reported in Scheme 3 is a two-electron two-proton reaction, but the yields of product $\mathbf{C}$ are very similar in the absence and in the presence of water (Table 1, entries 8 and 10). It is thus probable that, in the absence of water, the proton donor is the tetraalkylammonium cation, which undergoes Hoffman elimination after deprotonation.

Unexpectedly, the real challenge of this electrochemical synthesis was the product isolation in pure form. In fact, it was really difficult to completely separate the product from traces of the supporting electrolyte, which is probably due to the very polar nature of this product. After column chromatography followed by preparative thin layer chromatography (PLC), a pure product $\mathbf{C}$ was obtained.

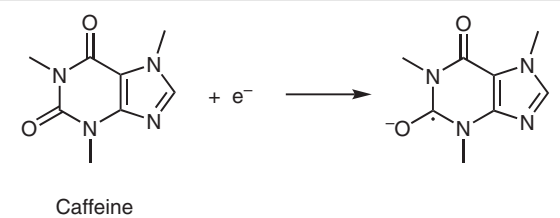

$$
\downarrow
$$

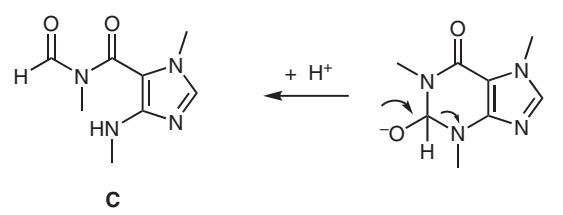

Scheme 3 Possible mechanism for the two-electron cathodic reduction of caffeine

In conclusion, the electrochemical methodology proved to be a valuable ally for organic synthesis, allowing to obtain $N$-Formyl- $N, 1$-dimethyl-4-(methylamino)- $1 H$-imidazole-5-carboxamide $\mathbf{C}^{14,15}$ This product was not obtainable 
(or with difficulty) by using classical chemical reactions and is a valuable starting material for the synthesis of enamides and related products.

In particular, the cathodic reduction of caffeine led to the uracil ring opening with the formation of a formylated product at the amide nitrogen atom (Scheme 2, product $\mathbf{C}$ ), whereas the classical chemical way led to the product formylated at the more basic amine nitrogen atom (Scheme 2 , product B). Moreover, the nature of the starting material (caffeine, biobased and thus renewable) renders this synthesis interesting from the 'greenness' point of view.

Last, the cathodic reactivity of caffeine is opposite to that of caffeinium salt, rendering the electrochemical methodology suitable to obtain, in one or two steps, an aminosubstituted uracil or an amino-substituted imidazole starting from the same molecule, caffeine.

\section{Funding Information}

This work was financially supported by Sapienza University of Rome (Project n. RM11715C7C8F258C).

\section{Acknowledgment}

The authors want to thank Mr Marco Di Pilato for his help whenever needed.

\section{Supporting Information}

Supporting information for this article is available online at https://doi.org/10.1055/s-0037-1611483.

\section{References and Notes}

(1) Fredholm, B. B. Methylxanthines; Springer: Berlin Heidelberg, 2011.

(2) (a) Huynh, H. V.; Han, Y.; Jothibasu, R.; Yang, J. A. Organometallics 2009, 28, 5395. (b) Landaeta, V. R.; Rodríguez-Lugo, R. E.; Rodríguez-Arias, E. N.; Coll-Gímez, D. S.; González, T. Transit. Met. Chem. 2010, 35, 165. (c) Luo, F.-T.; Lo, H.-K. J. Organomet. Chem. 2011, 696, 1262. (d) Zhang, J.-J.; Che, C.-M.; Ott, I. J. Organomet. Chem. 2015, 782, 37. (e) Herrmann, W. A.; Schütz, J.; Frey, G. D.; Herdtweck, E. Organometallics 2006, 25, 2437. (f) Kascatan-Nebioglu, A.; Melaiye, A.; Hindi, K.; Durmus, S.; Panzner, M. J.; Hogue, L. A.; Mallett, R. J.; Hovis, C. E.; Coughenour, M.; Crosby, S. D.; Milsted, A.; Ely, D. L.; Tessier, C. A.; Cannon, C. L.; Youngs, W. J. J. Med. Chem. 2006, 49, 6811. (g) Aweda, T. A.; Ikotun, O.; Mastren, T.; Cannon, C. L.; Wright, B.; Youngs, W. J.; Cutler, C.; Guthried, J.; Lapi, S. E. Med. Chem. Commun. 2013, 4, 1015. (h) Bertrand, B.; Stefan, L.; Pirrotta, M.; Monchaud, D.; Bodio, E.; Richard, P.; Le Gendre, P.; Warmerdam, E.; de Jager, M. H.; Groothuis, G. M. M.; Picquet, M.; Casini, A. Inorg. Chem. 2014, 53, 2296.
(3) (a) Bredereck, H.; Kupsch, G.; Wieland, H. Chem. Ber. 1959, 92, 566. (b) Hori, M.; Kataoka, T.; Shimizu, H.; Imai, E.; Matsumoto, Y.; Miura, I. Tetrahedron Lett. 1981, 22, 1259. (c) Hori, M.; Kataoka, T.; Shimizu, H.; Imai, E.; Matsumoto, Y. Chem. Pharm. Bull. 1985, 33, 3681. (d) Makhloufi, A.; Frank, W.; Ganter, C. Organometallics 2012, 31, 7272. (e) Martins, I. L.; Miranda, J. P.; Oliveira, N. G.; Fernandes, A. S.; Gonçalves, S.; Antunes, A. M. M. Molecules 2013, 18, 5251.

(4) Rosal, R.; Rodríguez, A.; Perdigón-Melón, J. A.; Petre, A.; GarcíaCalvo, E.; Gómez, M. J.; Agüera, A.; Fernández-Alba, A. R. Chemosphere 2009, 74, 825.

(5) Clark, P. G. K.; Lein, M.; Keyzers, R. A. Org. Biomol. Chem. 2012, $10,1725$.

(6) Švorc, L. Int. J. Electrochem. Sci. 2013, 8, 5755; and references therein.

(7) Pandolfi, F.; Mattiello, L.; Zane, D.; Feroci, M. Electrochim. Acta 2018, 280, 71 .

(8) Ohsaki, T.; Kuriki, T.; Ueda, T.; Sakakibara, J.; Asano, M. Chem. Pharm. Bull. 1986, 34, 3573.

(9) Pasqua, A. E.; Crawford, J. J.; Long, D.-L. Marquez R. 2012, 77, 2149.

(10) Liu, Y.; Li, D.; Park, C.-M. Angew. Chem. Int. Ed. 2011, 50, 7333.

(11) Chen, L.; Zou, X.; Zhao, H.; Xu, S. Org. Lett. 2017, 19, 3676.

(12) Usually electrolyses at constant potential ensure the selectivity of the reduction, because of the choice of working potential, and they are thus preferred. Nonetheless, in this case the reduction peak of caffeine and the onset potential for the reduction of a solvent-supporting electrolyte system are really close, making yields higher than $50 \%$ unobtainable. Because of the simplified setup for a galvanostatic electrolysis (only two electrodes, no reference electrode), we thus opted for constant current electrolyses.

(13) Dahm, C. E.; Peters, D. G. J. Electroanal. Chem. 1996, 402, 91.

(14) Experimental Procedure

Constant potential electrolysis was performed under a nitrogen atmosphere, at $25^{\circ} \mathrm{C}$, in a divided glass cell separated through a porous glass plug filled up with a layer of gel [i.e., methyl cellulose $0.5 \%$ vol dissolved in DMF-Bu $\mathrm{NBF}_{4}\left(1.0 \mathrm{~mol} \mathrm{dm}^{-3}\right)$ ]; Pt spirals (apparent area $0.8 \mathrm{~cm}^{2}$ ) were used as both cathode and anode. Catholyte: DMF ( $\left.5 \mathrm{~mL}, 0.1 \mathrm{M} \mathrm{DMF}-\mathrm{Bu}_{4} \mathrm{NBF}_{4}\right)$. Anolyte: the same solvent as the catholyte $(2 \mathrm{~mL})$. Starting caffeine $(0.5$ $\mathrm{mmol})$ [and water $(1.0 \mathrm{mmol})$ when reported in Table 1 ] were present in the catholyte during electrolysis. The electrolysis was stopped after $3 \mathrm{~F}$. At the end of the electrolysis, the solvent was eliminated under reduced pressure ( $15 \mathrm{~Pa}$ ) and the crude reaction mixture was analyzed by ${ }^{1} \mathrm{H}$ NMR spectroscopy. Product $\mathbf{C}$ was purified by flash column chromatography (eluent: $\mathrm{CH}_{2} \mathrm{Cl}_{2}-$ $\mathrm{MeOH}$ 70:30) and two subsequent PLCs with the same eluent.

(15) $\mathbf{N}$-Formyl- $\mathbf{N}, 1$-dimethyl-4-(methylamino)- $\mathbf{H}$-imidazole-5carboxamide C: ${ }^{1} \mathrm{H}$ NMR $\left(200 \mathrm{MHz}, \mathrm{CD}_{3} \mathrm{OD}\right): \delta=8.52(\mathrm{~s}, 1 \mathrm{H}$, CㅂO), 7.56 (s, 1 H, C2 $\underline{H}$ ), 3.90 (s, 3 H, 1-NMe), 3.15 (s, 3 H, 4$\mathrm{NMe}), 2.66$ (s, $3 \mathrm{H}, \mathrm{CONMe}) \mathrm{ppm} .{ }^{13} \mathrm{C}$ NMR $\left(50.3 \mathrm{MHz}, \mathrm{CDCl}_{3}\right)$ : $\delta=162.5,159.3,143.5,138.1,120.1,35.2,34.1,26.2 \mathrm{ppm}$. MS (ESI): $m / z\left[\mathrm{M}-28+\mathrm{H}^{+}\right]=169.2$. MS (EI): $m / z(\%)=[\mathrm{M}]^{+}$absent, $168(12)\left[\mathrm{M}^{+}-28\right], 138(4)\left[\mathrm{M}^{+}\right.$- NMeCHO], $110(85)(4)\left[\mathrm{M}^{+}\right.$ -CONMeCHO], 42 (100). 